\title{
Novos papéis e responsabilidade docente à luz das políticas educacionais e de formação de professores primários em Moçambique
}

\author{
MUGIME, Santa Mónica Julião ${ }^{1}$ \\ LEITE, Carlinda ${ }^{2}$ \\ MAHALAMBE, Feliciano M. ${ }^{3}$
}

\section{RESUMO}

O artigo, apoiado numa pesquisa documental da legislação sobre políticas educacionais e curriculares e de formação inicial de professores em Moçambique, discute os papéis e responsabilidades docentes à luz dessas políticas estabelecendo uma ponte com o que o currículo do ensino primário perspetiva. Sustentamos que a complexidade que atravessa o exercício da profissão docente, associada à responsabilidade da educação contribuir para o desenvolvimento positivo da sociedade, exigem do professor primário a capacidade de saber adaptar-se e lidar com os aspetos da recontextualização curricular (BERNSTEIN, 1993; LEITE; FERNANDES; FIGUEIREDO, 2018, 2019) e de reconfiguração do currículo (ALMEIDA; LEITE; SANTIAGO, 2013). A análise do discurso veiculado pelas políticas educacionais e curriculares aponta para a redefinição dos papéis dos professores e das responsabilidades a assumir, sobretudo, na forma de concretizar a educação.

Papéis dos professores. Responsabilidade docente. Políticas de educação. Formação de professores primários. Moçambique.

\section{New roles and teacher responsibility by education policies and primary teachers education in Mozambique}

\section{ABSTRACT}

The article, supported by documentary research focused on legislation about educational and curricular policies and initial teacher education in Mozambique, discusses the teacher's roles and their responsibilities related with these policies, establishing a bridge with the primary school curriculum perspectives.

\footnotetext{
${ }^{1}$ Doutorada em Educação/Currículo pela Escola Doutoral da Faculdade de Ciências de Educação e Psicologia da Universidade Pedagógica de Moçambique em Parceria com a Faculdade de Psicologia e de Ciências de Educação da Universidade de Porto em Portugal. Investigadora Auxiliar e docente na Academia de Ciências Policiais de Moçambique. E-mail smugime@yahoo.com.br

${ }^{2}$ Professora Catedrática da Universidade do Porto, na Faculdade de Psicologia e de Ciências da Educação e membro da direção do CIIE. É Professora emérita da Universidade do Porto, desde 2019. E-mail carlinda@fpce.up.pt

${ }^{3}$ Licenciado em Psicologia e Pedagogia na Faculdade de Ciências de Educação e Psicologia da Universidade Pedagógica de Moçambique. Director-Geral do Instituto Nacional de Exames, Certificação e Equivalências no Ministério da Educação e Desenvolvimento Humano. E-mail fmahalambe@gmail.com 
It is argued that the complexity of the teaching profession, associated with the education responsibility to contribute to a positive society development, requires the primary teachers to be able to adapt and deal with the curricular recontextualization (BERNSTEIN, 1993; FERNANDES; FIGUEIREDO, 2018, 2019) and the curriculum reconfiguration (ALMEIDA; LEITE; SANTIAGO, 2013). The discourse analysis conveyed by the educational and curricular policies points to the redefinition of the teacher's roles and the responsibilities that they need to assume, above all, in the way of carrying out the education.

Teachers roles. Teaching responsibility. Educational policies. Teachers primary education. Mozambique.

\section{INTRODUÇÃO}

O artigo discute os papéis e responsabilidades que recaem sobre os docentes do ensino primário, em Moçambique, à luz dos discursos veiculados nas políticas educacionais e curriculares e de formação inicial de professores. Estudos desta natureza têm vindo a ser desenvolvidos também em Portugal e no Brasil, estabelecendo relações entre políticas de formação de professores e políticas educacionais (ALMEIDA; LEITE; SANTIAGO, 2013; LEITE, 2012). Outros estudos, ainda, relacionam a Formação Inicial de Professores (FIP) com os processos decorrentes dos acordos de Bolonha (LEAL; LEITE, 2016; FERNANDES, 2012) ou buscam perceber os percursos e tendências recentes da FIP e o sentido de ser professor (LEITE, 2005, 2009). De igual modo, estudos relacionados com a prática reflexiva dos professores e a profissionalidade no trabalho docente têm dominado os debates acadêmicos (PERRENOUD, 2002; NÓVOA, 2009; 2017; FORMOSINHO, 2009; LOPES; CAVALCANTE; OLIVEIRA; HYPÓLITO, 2014). É no quadro desta temática que se situa este artigo e as ideias nele veiculadas.

Tendo como objetivo geral, e como já atrás foi referido, discutir sobre os novos papéis e responsabilidades que os professores do Ensino Primário, em Moçambique, devem assumir, o artigo dá conta de um estudo que analisa 0 discurso veiculado pelas políticas educacionais que orientam a FIP, confrontando-o com o que se espera da ação pedagógica e curricular docente. De um modo mais específico, o artigo: carateriza as políticas educacionais e de formação de professores primários em Moçambique nas últimas décadas; identifica as concepções presentes nas políticas curriculares de Formação de Professores Primários e Educadores de Adultos e sua relação com o currículo do Ensino Primário; discute sobre os novos papéis e novas responsabilidades que essas políticas atribuem aos professores no exercício da profissão docente. Neste sentido, o artigo, no estudo que apresenta, responde às seguintes questões:

Como se caraterizaram as políticas educacionais e de formação de professores primários em Moçambique nas últimas décadas?

Que concepções estão presentes no currículo de formação de professores primários e educadores de adultos em Moçambique? 
Que relações existem entre essas concepções de formação de professores e a ação pedagógica e curricular a desenvolver nas escolas?

Que novos papéis e responsabilidades são atribuídos aos professores à luz das políticas educacionais e de formação de professores?

Do ponto de vista das referências que nos orientam e que apoiam a análise dos papéis a atribuir aos professores e a serem por eles desempenhados, referimos que reconhecemos a importância destes serem decisores curriculares (LEITE; FERNANDES, 2010), isto é, de usarem o seu poder de agência (PRIESTLEY; BIESTA; ROBINSON, 2013, 2015) para que existam mais possibilidades de tornar as aprendizagens significativas para todos os alunos presentes nos espaços escolares e que têm como característica a diversidade. Sustentamos que a complexidade das situações que, nos quotidianos profissionais, são vividas pelos professores e as responsabilidades que lhes são requeridas no exercício da docência exigem do professor primário a capacidade de saber adaptar-se e lidar com os aspetos da recontextualização curricular (BERNSTEIN, 1993, LEITE; FERNANDES; FIGUEIREDO, 2018, 2019) e de reconfiguração do currículo (ALMEIDA; LEITE; SANTIAGO, 2013) para a sua concretização.

\section{Procedimentos metodológicos}

O estudo seguiu uma metodologia de orientação qualitativa de natureza descritiva, que recorreu à análise documental. Apoiando-nos em Lüdke e André, (2013, p. 38) a análise documental "pode constituir numa técnica valiosa de abordagem de dados qualitativos, seja complementando as informações obtidas por outras técnicas, seja desvelando aspectos novos de um tema ou problema". No caso do estudo a que se reporta este artigo, a pesquisa documental seguiu os seguintes passos: identificação e seleção dos documentos oficiais que orientam a formação de professores em vigor em Moçambique, designadamente: Plano Estratégico da Educação 2012-2016PEE (2012); Plano Curricular do Ensino Primário - PCEP (2015); Lei no 18/2018 de 28 de Dezembro, Lei do Sistema Nacional de Educação - SNE; Plano Curricular de Formação de Professores Primários e Educadores de Adultos PCFPPEA (2019). Para a análise desses documentos, foram cumpridos os procedimentos: leitura e marcação no texto dos enunciados que veiculam um discurso de responsabilidade profissional e responsabilidade social (NÓVOA, 2009); transcrição de excertos do texto do documento para uma matriz que continha as dimensões de análise; interpretação desses discursos tomando em consideração as referências teóricas que nos orientam e que suportam o estudo.

A análise seguiu também a técnica de análise de conteúdo que de acordo com Bardin (2011) corresponde a uma metodologia que permite interpretar de forma sistemática o conteúdo da mensagem, quer textual ou gráfica, quer discursiva. No caso deste estudo, os excertos dos documentos recolhidos foram analisados em função do conteúdo na base das seguintes categorias de análise: discursos sobre profissionalização da profissão docente; 
modo como o discurso de responsabilidade profissional e responsabilidade social do professor reflete-se na ação docente.

\section{Políticas educacionais e de formação de professores primários em Moçambique (1990 a 2019)}

Moçambique, desde a década de 90 (séc. XX), contou com um conjunto de reformas educacionais que se traduziram na aprovação de leis e ou regulamentos sobre o sistema educativo. A aprovação da Lei nำ6/92, de 6 de Maio sobre o SNE (Sistema Nacional da Educação) em substituição da Lei no 4/83, de 23 de Março que cria o SNE; a Resolução n- 8/95, de 22 de Agosto que define a Política Nacional de Educação (PNE); a conceção de planos estratégicos para o Setor da Educação (Plano Estratégico para o Setor de Educação de 1999 a 2005; o Plano Estratégico da Educação e Cultura de 2006 a 2011; o Plano Estratégico de Educação de 2012 a 2016), a Estratégia de Formação de Professores (2004 a 2015) representam, em parte essas reformas.

As referidas reformas encontram a sua justificação nas transformações políticas, econômicas e sociais que o país registou a partir de 1990, de entre as quais mencionam-se: a aprovação da nova Constituição e a introdução do multipartidarismo, assinatura dos Acordos de Paz em Roma em 1992 e a cessação da guerra de desestabilização que durou os 16 anos e a realização das primeiras eleições democráticas em 1994.

A par destas transformações, no contexto internacional, a Declaração Mundial sobre Educação para Todos, ratificada em Jomtien, na Tailândia em 1990, os desafios lançados através do relatório para a UNESCO sobre a Educação para o Século XXI (DELORS et al., 2010), influenciaram sobre maneira as políticas educacionais e de formação de professores em Moçambique. Estes instrumentos veem a educação como indispensável ao progresso da humanidade, no que respeita à consolidação dos ideais da paz, da liberdade e de justiça social (CONNELL, 1999; SANTOMÉ, 2013). Há que reconhecer que, com o relatório da UNESCO atrás referenciado, anunciou a necessidade de superar tensões entre o global e o local, isto é, tornar as pessoas cidadãos do mundo, sem perder de vista as suas raízes, ou seja, trouxe à reflexão a tensão entre o global e o local, a tensão entre a tradição e modernidade (adaptar-se sem se negar a si mesmo), o que justifica e sugere alterações nos sistemas educativos. Outro aspeto fundamental que o relatório traz à tona, é a necessidade de revalorização da dimensão ética e cultural da educação, a criatividade e inovação a que os professores e os alunos são chamados, o que se traduz num conceito mais profundo sobre educação, expresso na educação ao longo da vida.

Por sua vez, a Declaração de Salamanca (1994) realçou, igualmente, a necessidade de a escola criar condições para que todos os alunos nela presentes tivessem sucesso. Foi influenciado por estas concepções e/ou exigências para a educação, veiculadas a nível internacional, que Moçambique 
procurou adequar o Sistema Educativo reformulando as políticas educacionais e curriculares.

As políticas educacionais e curriculares resultantes destas transformações requereram novas formas de pensar e de fazer a educação. Por isso, corresponderam a alterações nos aspetos estruturais e organizacionais da educação e do ensino, que dão conta às questões de educação de qualidade, educação inclusiva, educação equitativa e democrática ou participativa e, ademais, promotora de valores da cidadania, da paz, da solidariedade, da sustentabilidade e, acima de tudo, orientada para a resolução de problemas concretos dos alunos, das suas vidas e das vidas das suas famílias.

É neste sentido que as leis sobre o SNE que foram sendo aprovadas, a Lei $n^{\circ}$ 6/92 de 6 de Maio que alterou a Lei $n^{\circ}$ 4/83 de 23 de Março, que criou 0 SNE, e a Lei no 18/2018 de 28 de Dezembro, mais recentemente aprovada, nas concepções de educação que veiculam são a réplica dos discursos das políticas educacionais globais. A título de exemplo, a Lei $n^{\circ}$ 6/92, de 6 de Maio apregoava como objetivos do SNE a erradicação do analfabetismo, a garantia do ensino básico para todos, a formação de cidadãos com uma sólida formação científica, técnica, cultural e física e uma elevada educação moral, cívica e patriótica. Por sua vez, a Política Nacional de Educação aprovada pela Resolução no 8/95 de 22 de Agosto, por sua vez, enfatizou a necessidade de se assegurar o acesso à educação a um número cada vez maior de utentes, assim como, entre outros aspetos, a melhoria da qualidade da educação de todos os níveis e tipos de ensino e a massificação do acesso à educação.

Mais recentemente, a Lei no 18/2018, de 28 de Dezembro do Sistema Nacional da Educação reajusta o quadro geral do SNE e revoga as disposições contidas na Lei no 6/92 de 6 de Maio, enfatizando nos seus princípios gerais que o SNE visa: proporcionar uma educação, cultura, formação e desenvolvimento humano equilibrado e inclusivo enquanto direito de todos os moçambicanos; promover uma cidadania responsável e democrática; proporcionar o desenvolvimento da consciência patriótica e de valores da paz, do diálogo e a valorização da família e do ambiente. Ainda segundo esta lei, a Educação em Moçambique deve privilegiar a democratização do ensino, a justiça, a igualdade de oportunidades de acesso, 0 desenvolvimento sustentável, a preparação integral do ser humano atento e integrado à vida política, econômica e social, o respeito pelos Direitos Humanos, e o desenvolvimento do espírito de tolerância, da solidariedade e o respeito ao próximo.

O mesmo pode ser dito em relação aos planos estratégicos que foram sendo definidos no Sector da Educação, com ênfase para os dois últimos, o de 2006 a 2011 e o de 2012 a 2016, em que se lê, em ambos, a necessidade de expansão do acesso à educação, a melhoria da qualidade, a manutenção de estudantes até à $7^{\text {a }}$ classe, a reafirmação da educação como um direito fundamental, a qualidade e equidade do ensino, a educação inclusiva, democrática e justa e orientada para a cidadania, a igualdade de oportunidades de acesso (...), entre outros aspetos. 
Como afirmámos acima, trata-se de uma réplica dos discursos das políticas educacionais do nível global que ditam o tipo e a forma de educação que deve ser desenvolvida em países da periferia, sem ter em conta a realidade concreta dos mesmos. A este propósito, Almeida, Leite e Santiago (2013, p.121) referem que,

as políticas educacionais envolvem aspetos que explicam e legitimam decisões que estão imbricadas em uma política maior que busca produzir e atingir objetivos articulados. Muita das vezes, essas políticas baseiam-se na lógica mercadológica, assente nos ideais do liberalismo económico.

É esta realidade que o sistema educativo moçambicano vivencia o que talvez justifique a questão da continuidade do discurso que caracteriza a transição de uma política para outra, dando a impressão da não concretização do discurso veiculado nas políticas no contexto da prática ou mesmo da implementação da política.

Todavia, à luz das novas concepções sobre educação presentes nestes discursos políticos, as políticas curriculares de formação inicial de professores em Moçambique também sofreram alterações. Na base destes diplomas legais são atribuídos aos professores novos papéis e novas responsabilidade no exercício docente, no que concerne ao funcionamento da escola e ao cumprimento das metas de aprendizagem sugeridas por esses discursos políticos. Ou seja, a formação de professores passou a ser organizada em função do discurso expresso nas políticas educacionais públicas. É no âmbito desta linha política que os conhecimentos e as competências exigidos aos professores passaram a ser, essencialmente, os relacionados com um ensino de qualidade, inclusivo, integrado, democrático, centrado no aluno e que proporcione valores de cidadania, de solidariedade, do patriotismo, entre outros (Plano Curricular de Formação de Professores Primários e Educadores de Adultos - PCFPPEA, 2019; Plano Estratégico da Educação 2012-2016- PEE, 2012).

Para a concretização desse ensino de qualidade, é exigido aos professores a reflexividade e a profissionalidade no exercício do seu ofício, ou seja, é referido que a formação de professores é orientada por um novo paradigma, o paradigma reflexivo ou do professor crítico e profissional (PCFPPEA, 2019, p. 10). Na perspetiva deste paradigma é necessário

desenvolver nos futuros professores o espírito crítico e prepará-los para a ação reflexiva sobre e na prática pedagógica com vista a formação de um professor profissional que sabe analisar, refletir decidir e justificar (PCFPPEA, 2019, p.10) 
Como tem sido reconhecido, uma prática reflexiva requer uma relação analítica com a ação no exercício cotidiano da profissão. Leite, Fernandes e Mouraz (2016, p. 49) referem que, um

"profissional reflexivo" ou um "prático reflexivo" é aquele agente
educativo que, com independência e responsabilidade, e
apoiando-se quer na sua experiência, quer nos conhecimentos
relacionados com as situações em análise, desenvolve uma
prática apoiada numa estratégia heurística onde a reflexão
funciona como elemento auto-formativo e estruturador da ação.

É nesta linha, e como é afirmado por Perrenoud (2001, pp. 10-11), que a profissionalização do ofício do professor poderá ser entendida como um importante acréscimo à formação, ultrapassando o domínio dos conteúdos a serem ensinados. Ainda na percepção deste autor, um profissional deve reunir as competências de alguém que identifica o problema, apresenta-o, imagina e aplica uma solução e, por fim, garante seu acompanhamento. Nessa lógica, o profissional é aquele que constrói a sua prática no cotidiano, o que significa que o professor profissional será aquele que saberá na prática ou na sua ação didática construir a sua prática em função do contexto. Para isso, é necessário mobilizar competências de reflexão e dominar saberes que estão para além dos conteúdos acadêmicos.

Retomando os discursos expressos nas políticas educacionais no período em análise, há que reconhecer que eles contribuíram para a diversidade de modelos de formação de professores primários e das instituições de formação de professores. De 1992 à atualidade, com o crescimento da rede escolar, sentiu-se a necessidade da conversão dos Institutos do Magistérios Primários (IMAP) que formavam professores para o Ensino Primário do Segundo Grau (EP2), com o perfil de ingresso de 10 classe, em Institutos de Formação de Professores (IFPs) (Ministério da Educação e Desenvolvimento Humano - MINEDH, 2017). Os IFPs passaram a formar professores para o ensino primário em geral, do primeiro e do segundo ciclos, com o perfil de ingresso de $10^{\underline{a}}$ e $12^{\underline{a}}$ classes, respetivamente.

Com a expansão cada vez maior da rede escolar, e para suprir as necessidades em professores, eram recrutadas pessoas com o nível de 10a Classe, sem formação psicopedagógica para exercer a profissão docente. Em 2007, para fazer face à falta de professores, foram aprovados novos modelos de formação de professores para o Ensino Primário, um que dizia respeito à formação inicial de um ano complementada com a formação em exercício ou contínua, cujo nível para ingresso era a $10^{\underline{a}}$ classe para depois lecionar da $1^{\text {a }}$ à $7^{\text {a }}$ classe (Idem). Em 2012, o MINED introduziu o modelo de formação de 10a classe mais três anos que funcionava em paralelo com o de $10^{\underline{a}}$ Classe mais 
um ano e, mais recentemente, foi introduzido o modelo da $12^{a}$ classe mais três anos.

Como se depreende, os modelos de formação de professores foram variando quanto ao perfil de entrada e quanto à duração do curso, para não falar de outros vários modelos implementados no período anterior a 1990. O quadro 1 sistematiza essa trajetória.

\section{Quadro 1: Modelos de formação de professores Primários em Moçambique de 1975 a 2019}

\begin{tabular}{|c|c|c|}
\hline $\begin{array}{l}\text { Modelo de formação de professores } \\
\text { primários }\end{array}$ & $\begin{array}{ll}\begin{array}{l}\text { Período } \\
\text { vigência } \\
\text { curso }\end{array} & \text { do } \\
\end{array}$ & $\begin{array}{l}\text { Instituição } \\
\text { formadora }\end{array}$ \\
\hline $\begin{array}{l}\text { Modelo de formação de professores de } 6^{\underline{a}} \\
\text { Classe }+1 \text { ano }\end{array}$ & 1982 a 1983 & $\begin{array}{l}\text { Escola de Formação } \\
\text { e Educação de } \\
\text { professores }- \text { EFEP }\end{array}$ \\
\hline $\begin{array}{l}\text { Modelo de formação de professores de } 6^{\text {a }} \\
\text { Classe+2 ano }\end{array}$ & 1982 a 1983 & EFEP \\
\hline $\begin{array}{l}\text { Modelo de formação de professores de } 6^{\underline{a}}+3 \\
\text { anos }\end{array}$ & 1983 a 1991 & $\begin{array}{l}\text { Centros de Formação } \\
\text { de pressores } \\
\text { primários CFPP. }\end{array}$ \\
\hline $\begin{array}{l}\text { Modelo de formação de professores de } 7^{\underline{a}}+3 \\
\text { anos }\end{array}$ & 1991 a 2007 & CFPP \\
\hline $\begin{array}{l}\text { Modelo de formação de Professores de } 7^{\underline{a}+} \\
2+3\end{array}$ & 1999 a 2003 & CFPP \\
\hline $\begin{array}{l}\text { Modelo de formação de Professores de } 10^{\underline{a}}+ \\
2\end{array}$ & 1998 a 2007 & $\begin{array}{l}\text { Institutos de } \\
\text { Magistério Primário - } \\
\text { IMAP }\end{array}$ \\
\hline $\begin{array}{l}\text { Modelo de formação de Professores de } \\
10^{a^{a}}+1+1\end{array}$ & 1999 a 2004 & IMAP \\
\hline $\begin{array}{l}\text { Modelo de formação de Professores de } \\
10^{-}+1\end{array}$ & 2007 a 2019 & $\begin{array}{l}\text { Institutos de formação } \\
\text { de professores - IFPs }\end{array}$ \\
\hline $\begin{array}{l}\text { Modelo de formação de Professores de } \\
10^{-}+3\end{array}$ & 2012 a 2019 & IFPs \\
\hline $\begin{array}{l}\text { Modelo de formação de Professores de } \\
12^{2}+3\end{array}$ & 2019 & IFPs \\
\hline $\begin{array}{l}\text { Modelo de formação de Professores de } \\
10^{-}+2,5 \text { anos }\end{array}$ & & ADPP \\
\hline
\end{tabular}

Fonte: elaborado pelos autores a partir dos dados do MINEDH, 2017; MAHALAMBE, 2011.

A diversidade dos modelos de formação de professores corresponde, por sua vez, à diversidade do perfil dos atuais professores em exercício no Ensino Primário, já que os planos de estudos diferem um do outro. No entanto, tanto os professores de um ou do outro modelo deverão adequar a sua ação pedagógica de modo a concretizar o discurso atual presente nas políticas 
educacionais e curriculares que se consubstancia no professor reflexivo e profissional, o que sugere que o professor deverá assumir o papel de "recontextualizador e configurador do currículo" no processo de ensinoaprendizagem. Este discurso, está em linha com a posição de Leal e Leite $(2017$, p. 6) quando afirma que,

nestes tempos de instabilidade, que os desafios da pósmodernidade obrigam à criação de mecanismos estratégicos de adequação a novas realidades, exigem que os professores desenvolvam competências holísticas, plurais e multifacetadas, capazes de apoiar a gestão de novas situações que os cotidianos vão apresentando.

É para esta exigência que apontam os diferentes perfis que caracterizam os professores que atuam no Ensino Primário e que os desafiam a atenderem a uma educação primária que se pretende que seja de qualidade, inclusiva, que atenda às questões da diversidade cultural e que promova nos alunos os valores de cidadania responsável, democrática, da consciência patriótica e dos valores da paz, diálogo (art. 3 da lei no 18/2018 do SNE, Princípios orientadores). São estas exigências que requerem do professor um agir diferente do que era pedido quando a sua função se limitava a transmitir um conhecimento considerado único e que seria compreendido de forma igual por todos os alunos. Neste desafio, e como atrás já afirmámos, espera-se que os professores sejam decisores curriculares (LEITE; FERNANDES, 2010) e que usem positivamente 0 seu poder de agência (PRIESTLEY; BIESTA; ROBINSON, 2013, 2015) para conseguirem que todos os alunos, tendo por base as suas experiências de vida se disponham a reconhecer e a conhecer outras experiências e outros saberes.

É no quadro desta concepção de educação e dos papéis dos professores que se espera que a formação inicial de professores em Moçambique venha a ter reflexos ao nível da prática, conduzindo os professores a saberem lidar com as situações diversas que o exercício da docência coloca. Só assim fará sentido o paradigma que se deseja e que orientam a FIP.

\section{Concepções presentes nas políticas curriculares de formação de Professores Primários e sua relação com o currículo do Ensino Primário}

Para a análise das concepções presentes nas políticas curriculares de formação de professores buscámos para análise os seguintes documentos oficiais: Lei oํ 18/2018 de 28 de Dezembro sobre o SNE; Plano Curricular do Curso de Formação de Professores Primários e Educadores de Adultos (2019). 
Para discutir a relação entre estas concepções e o que se projeta para 0 Ensino Primário, analisámos também o Plano curricular do Ensino Primário (2015). Para o efeito, considerámos as seguintes categorias ou dimensões de análise: discursos sobre profissionalização da profissão docente; discursos sobre responsabilidade profissional versus responsabilidade social do professor e ação docente.

Sobre a profissionalização da profissão docente, os documentos analisados expressam as seguintes concepções: formação integral e de qualidade; desenvolvimento de iniciativa criadora da capacidade de estudo individual e de assimilação crítica dos conhecimentos; ligação teoria e prática; formação do cidadão com uma sólida preparação científica, técnica, cultural e física; promoção do uso de novas tecnologias de informação e comunicação; formação de um professor educador e profissional; formação de cientistas e especialistas devidamente qualificados; garantir uma formação integral (art. 3 e 4 da Lei no 18/2018 do SNE, dos princípios gerais).

No Plano Curricular de Formação de Professores e Educadores de Adultos (2019) está presente, nos princípios orientadores, a ideia da articulação entre a formação científica e pedagógica orientada para a prática reflexiva e contextualizada e a transferência de competências para a prática profissional futura. O mesmo documento refere que os desafios do currículo de formação de professores são adequar a formação ao programa quinquenal do governo 2015-2019, que vinca a melhoria da qualidade da educação.

Relativamente ao discurso sobre responsabilidade profissional versus responsabilidade social do professor e ação docente, a mesma lei expressa a ideia de promoção da cidadania responsável e democrática, da consciência patriótica e dos valores da paz, diálogo, família e ambiente; preparar integralmente o Homem para intervir na vida política económica e social de acordo com os padrões morais e éticos aceites na sociedade; respeito pelos Direitos Humanos (DH); cultivar o espírito de tolerância, da solidariedade e do respeito ao próximo e às diferenças; ligação escola comunidade; contribuir para a igualdade de oportunidades de acesso à educação e ao acesso escolar; valorização das línguas, culturas e história moçambicanas (idem, art. 3 e 4).

O Plano curricular de Formação de Professores e Educadores de Adultos (2019) expressa que a formação deverá dar conta da questão do multilinguismo e a multiculturalidade da sociedade moçambicana, dos objetivos do desenvolvimento sustentável (ODS) e da Agenda 2063 que almeja uma África pacífica e segura, deixando transparecer a responsabilidade difusa que recai sobre o professor que deverá oferecer um ensino e promover uma aprendizagem à altura de responder a estas novas exigências. 
Tendo em atenção o que é enunciado nestes documentos, em termos de concepções, notamos que são muitas as responsabilidades que se atribuem aos professores e, ao que tudo indica, projetam que estes assumam distintos papéis na sua prática profissional. Os discursos presentes nos documentos analisados atribuem à figura do professor, para além da atividade de ensino, um enorme conjunto de responsabilidades sociais e políticas. Esta forma de conceber a educação requer a formação de um Bom Professor, um professor comprometido socialmente e com a realidade que vive, um professor que intervém no espaço público de educação enquanto parte do seu ethos profissional docente (NÓVOA, 2009, p.31). A esse respeito, Leite e Fernandes (2010, p. 199) consideram que, nos dias de hoje, são muitos os desafios a que os professores têm de responder, no quadro de mandatos educacionais que atribuem às instituições escolares, para além da tarefa de ensino e de formação, um conjunto de responsabilidades sociais, situação que cria também enormes responsabilidades à formação inicial. Como já atrás referimos, a considerar as concepções de educação veiculadas no discurso das políticas, espera-se dos professores novas formas de agir e de fazer a docência que, ao mesmo tempo que promovem a aprendizagem do aluno, contribuem também para que desenvolva competências pessoais e sociais. É a este propósito que Formosinho (2009) se refere a uma formação de professores orientada para a qualificação científica e didática, mas também de formação pessoal e social.

Em síntese, de um modo geral o discurso das políticas educacionais e curriculares coloca ao Professor desafios que pressupõem, por um lado, a existência de motivação, condições materiais e por outro lado, a sua vontade em participar das transformações que se impõem na educação moçambicana. Além disso, estas transformações exigem do Professor o espírito de partilha de experiências, numa realidade marcada por uma pluralidade de modelos que caracterizaram e caracterizam a formação de professores em Moçambique.

\section{Papéis dos professores do Ensino Primário à luz da política educacional e curricular}

Se no passado ser professor ou ser um bom professor correspondia a conseguir despertar a atenção dos alunos para os conteúdos do programa que o professor expunha e explicava para serem compreendidos pelos alunos, ou seja, quando o professor usava um modelo tradicional de ensino e de racionalidade académica (LEITE, 2002), hoje à escola e ao professor são atribuídos novos papéis e novas responsabilidades. Esses novos papéis e responsabilidades derivam do reconhecimento da dimensão social da educação e dos novos paradigmas que orientam a educação em Moçambique. Referimo-nos aos paradigmas reflexivo, de educação democrática, 
participativa, equitativa, de educação de qualidade e de educação inclusiva que implicam dos professores conhecimentos para agirem como conceptores e decisores curriculares de modo a adequarem e recontextualizarem o currículo para assegurar a aprendizagem e a formação ampla de todos os alunos.

Assim, com estes novos papéis dos docentes almeja-se que recorram a metodologias ativas que permitam fazer uma articulação entre os saberes teóricos e os saberes práticos, que mantenham um contato permanente com professores experientes, que centrem os processos de ensino-aprendizagem no estudante, que saibam trabalhar as questões da transversalidade, da integração, mas também que atendam a questões do currículo local, do qual depende a sua capacidade de ir selecionado conteúdos de interesse para a comunidade onde a escola está inserida e trazê-los para o currículo escolar (PCFPPEA, 2019).

Como se pode constatar, os novos papéis dos professores tornam o campo da ação docente mais complexo, quer no campo acadêmico, quer no campo profissional, situação para a qual vale a pena ter em atenção o que refere Nóvoa (2017, p. 1118):

(...) sempre se procurou organizar a formação de professores a partir de uma lista de atributos ou de qualidades do "bom professor". Nas últimas décadas assistiu-se à vulgarização de longas listas de competência, que procuram dar conta de tudo o que um professor deve ser capaz de pôr em ação no decurso do seu trabalho docente.

Esta realidade, idêntica ou próxima do que tem vindo a acontecer em Moçambique, clarifica a nossa posição de que a profissão docente e os processos de formação estão a passar por um movimento de transferência dos papéis e das responsabilidades tradicionalmente conferidas aos professores através do que se pode se chamar por socialização profissional (idem). O que estamos, pois, a referenciar é que o discurso da política educativa induz o Professor a agir não apenas como indivíduo que ensina os conteúdos programáticos, mas também a assumir outros papéis que a sociedade lhe atribui. No entanto, há que refletir sobre se essa transferência que se opera no campo da ação pedagógica e didática do Professor através do discurso das políticas está à altura de produzir inovações no exercício profissional dos professores ao nível da escola primária. Ou, olhando a situação por outra perspectiva, o facto de o discurso presente nas políticas educacionais e curriculares de formação de professores ser o reflexo do que tem vindo a ser determinado pelas políticas mais globais sobre a educação, sem ter em conta a realidade moçambicana, pode contribuir para o desfasamento cada vez maior entre o que é pretendido e o que é concretizado na prática profissional. 
Muitas das competências requeridas para o graduado do Ensino Primário requerem o recurso à transversalidade. Tenha-se em consideração que o Plano de Estudos do Ensino Primário compreende três áreas curriculares: Comunicação e Ciências Sociais, Matemática e Ciências Naturais e atividade Prática e Tecnológica. Ao mesmo tempo que se exige que o perfil do graduado seja multifacetado com uma lista de competências a desenvolver, como por exemplo: amor pela vida; conhecer os seus direitos e deveres; respeitar os outros, particularmente os mais velhos e pessoas com deficiência; ter amor à pátria; respeitar os bens públicos e privados; respeitar as particularidades individuais; participar em atividades de interesse coletivo; promover ações para a proteção do ambiente; respeitar a diversidade cultural do país; valorizar a sua língua e a dos outros; usar, de forma racional, os recursos da natureza; responsabilidade; curiosidade; liberdade, entre outros aspetos.

O que estamos, pois, a afirmar é que, o agir e ser do professor, ou seja, o assumir de novos papéis e responsabilidade docentes no contexto da escola primária moçambicana ultrapassa as fronteiras do espaço escolar. Como refere Formosinho (2009 p.179), a função docente, antes restrita à sala de aula, tem vindo a aumentar consideravelmente a sua área de ação dando lugar ao que se chama de novas funções da escola de massas. Essas funções exigem, não só o aproximar do discurso da política educativa à prática pedagógica, como também a ideia de cada um construir sua posição como professor, aprender a sentir como professor (NÓVOA; 2017, p. 1123).

\section{Considerações finais}

Como afirmámos na introdução deste artigo, interessava discutir sobre os novos papéis e responsabilidades que os professores do Ensino Primário em Moçambique devem assumir à luz das políticas educacionais e curriculares que orientam a FIP. A ideia central foi analisar a forma como os discursos dessas políticas posicionam os professores do Ensino Primário enquanto recontextualizadores e configuradores do currículo na sua ação pedagógicodidático. Como ao longo do artigo referimos, a análise realizada indica que 0 discurso das políticas educacionais e curriculares de formação de professores, assim como o discurso do currículo do Ensino Primário, concorrem para a redefinição dos papéis e das responsabilidades do professor no exercício da sua profissão docente. Esta constatação resulta do reconhecimento da dimensão social que recai sobre a escola, e de que são exemplo educar os alunos a desenvolverem valores para cidadania, para a paz, para o patriotismo, para a sustentabilidade, aspetos que não cabem apenas no domínio da aprendizagem de conteúdos lecionados na sala aula. Os professores são assim colocados perante novos desafios profissionais que se situam, entre a 
tradicional função de promoção de aprendizagem e a função socializadora, dada a responsabilização que se Ihes atribui na função educativa.

À nova concepção do professor como profissional reflexivo que usa a sua agência, acresce a responsabilidade profissional sobretudo na forma de entender e de concretizar uma educação que contemple, para além da dimensão cognitiva e dos conteúdos, a dimensão da formação pessoal e social dos alunos com quem trabalha. À transversalidade que lhe é exigida na mediação do processo de ensino-aprendizagem acresce, cada vez mais, essa responsabilidade, no sentido de desenvolver saberes transversais fora do contexto das disciplinas escolares prescritas no currículo (Línguas, Matemática, Ciências Sociais e Naturais). Em síntese, os discursos das políticas educativas impõem um conjunto de obrigações ao professor fora dos tradicionais saberes das disciplinas escolares que, ao mesmo tempo devem ser encarados como desafios sociais à profissão, impõem, para a concretização, novos desafios aos modelos de formação inicial de professores.

\section{Referências Bibliográficas}

ALMEIDA, Lucinalva; LEITE, Carlinda; SANTIAGO, Eliete. Um olhar sobre as políticas curriculares para a formação de professores no Brasil e em Portugal na transição do Século XX para o Século XXI. Revista Lusófona de Educação, 23, pp.119-135, 2013.

BARDIN, Laurence. Análise de conteúdo. Lisboa: Edições 70, 2011.

BERNSTEIN, Basil. La estructura del discurso pedagógico. Madrid:

Morata, 1993.

CONNELL, Ronald. Escuelas e justicia social. Madrid: Ediciones Morata, 1999.

DELORS, Jaques, et al. Educação um tesouro a descobrir. Relatório para UNESCO da Comissão Internacional sobre Educação para o século XXI. Paris: UNESCO, 2010.

FORMOSINHO, João, Formação de Professores - Aprendizagem Profissional e Acção Docente. Porto: Porto Editora, 2009.

LEAL, Ana Rita; LEITE, Carlinda. Política de formação inicial de professores em Portugal decorrente de Bolonha: Posições da comunidade científica. Revista Interterritórios, v. 3, n. 4, pp.5-30, 2017.

LEITE, Carlinda. Percursos e tendências recentes da formação de professores em Portugal. Educação (BR), 1 (3), pp. 371-389, 2005.

LEITE, Carlinda. Ser professor nos dias de hoje, formar professores num mundo em mudança. Educação-Revista. Centro de Educação da UFSM, 34 (32), pp.255-264, 2009. 
Novos papéis e responsabilidade docente à luz das políticas educacionais e de formação de professores primários em Moçambique

LEITE, Carlinda; FERNANDES, Preciosa. Desafios aos professores na construção de mudanças educacionais e curriculares: Que possibilidades e que constrangimentos. Educação, v. 33, n. 3, pp. 198-204, set./dez., 2010.

LEITE, Carlinda. A formação inicial de professores no quadro dos compromissos de Bolonha - contributos para uma reflexão sobre o que foi instituído em Portugal. Revista Brasileira de pesquisa sobre formação docente v.04, n.07, p.10-18. Julh/dez., 2012.

LEITE, Carlinda; FERNANDES, Preciosa; MOURAZ, Ana. O lugar da reflexão na formação e no desenvolvimento profissional de professores dos ensinos básico e secundário em Portugal, Tópicos Educacionais, Recife, v.22, n.1, 45-67, jan/jun, 2016.

LEITE, Carlinda; FERNANDES, Preciosa; FIGUEIREDO, Carla. National curriculum vs curricular contextualisation: teachers' perspectives, Educational Studies, 2019. https://www.tandfonline.com/doi/full/10.1080/03055698.2019.1570083

LEITE, Carlinda; FERNANDES, Preciosa; FIGUEIREDO, Carla. Challenges of curricular contextualisation: Teachers' perspectives. The Australian Educational Researcher. Advance online publication. doi:10.1007/s13384-018-0271-1.

LOPES, Amélia; CAVALCANTE, Auxiliadora; OLIVEIRA, Dalila; Hypólito, Álvaro (orgs.). Trabalho docente. Políticas, práticas e investigação: Pontes para mudança. U. Porto: CIIE, 2014.

LUDKE, Menga; ANDRÉ, Marli Eliza. Pesquisa em educação: abordagens qualitativas. 2.ed. Rio de Janeiro: EPU, 2013.

MAHALAMBE, Feliciano. Trajectória sobre o sistema de formação de professores em Moçambique (Ensino Primário e Ensino Secundário). In LURDES, Serrasina, et al. Formação contínua. Relatos e Reflexões. Lisboa: Instituto Politécnico de Lisboa. pp, 265-276, 2011.

Ministério de Educação. Estratégia de Formação de professores 2004-2015.

Proposta de Políticas. Maputo: MINED, 2004.

Ministério de Educação e Desenvolvimento Humano. Estudo Holístico da situação do professor em Moçambique. Maputo: Académica, 2017.

NÓVOA, António Professores: Imagens do futuro presente. Lisboa: Educa, 2009.

NÓVOA, António. Firmar a posição como professor, afirmar a profissão docente.

Cadernos de pesquisa, v. 47, n.166, pp. 1106 -1133, out/dez., 2017.

PERRENOUD, Philippe. A Prática Reflexiva no Ofício de Professor:

Profissionalização e Razão Pedagógica. Porto Alegre - São Paulo: Artmed Editora, S.A, 2008.

PRIESTLEY, Mark; BIESTA, GerT; \& ROBINSON, Sarah. Teachers as agents of charge: Teacher agency and emerging models of curriculum. In M. Priestley; G. Biesta, Reinventing the curriculum: New trends in curriculum police and practice, $\mathrm{pp}$. 187-206. London: Bloomsbury Academic, 2013. 
PRIESTLEY, Mark; BIESTA, Gert; \& ROBINSON, Sarah. Teacher agency: what is it and why does it matter? In R. Kneyber; J. Evers, Flip the system: Changing education from the bottom up, pp. 134-148. London: Routledge, 2015.

República de Moçambique. Plano curricular do Ensino Básico, Maputo: Ministério da Educação - INDE, 2003.

República de Moçambique. Plano Estratégico de Educação e Cultura 2006-2010/11. Maputo: Conselho de Ministros, 2006.

República de Moçambique. Plano Estratégico de Educação e Cultura 2012-2016. Maputo: MINED, 2012.

República de Moçambique. Plano curricular do Ensino Primário. Maputo. Ministério da Educação - INDE, 2015.

República de Moçambique. Lei no 18/2018 de 28 de Dezembro, Lei do Sistema Nacional de Educação. In Boletim da República I Série n. 254, Moçambique, 2018.

República de Moçambique. Plano curricular. Curso de Formação de Professores do Ensino Primário e Educadores de Adultos. Maputo: Ministério da Educação INDE, 2019.

SANTOMÉ, Jurjo Torres. Currículo escolar e justiça social: o Cavalo de Troia da Educação. Porto Alegre: Penso, 2013.

UNESCO. Declaração mundial sobre Educação Para Todos: Satisfação das necessidades básicas de aprendizagem. [Online] Disponível em www.unesdoc.unesco.org. Jomtien: 1990. Arquivo consultado em 19/05/19.

UNESCO. Declaração de Salamanca. Sobre Princípios, Políticas e Práticas na Área das Necessidades Educativas Especiais. [Online] 1994. Disponível em http://portal.mec.gov.br/seesp/arquivos/pdf/salamanca.pdf. Arquivo consultado em 20/05/19. 